\title{
PEMANFAATAN BAMBU OLEH MASYARAKAT DESA BABANE KECAMATAN SAMALANTAN KABUPATEN BENGKAYANG
}

\author{
Usman \\ Fakultas Kehutanan Universitas Tanjungpura, Jalan Imam Bonjol Pontianak 78124 \\ Email: usmanuwai81@gmail.com
}

\begin{abstract}
Bamboo is a very useful plant for the economic life of the community. Until now, bamboo has been used very widely, ranging from the use of the simplest technology to be used high technology on an industrial scale. Traditionally, bamboo is commonly used for various purposes such as household appliances, handicrafts and groceries. The purpose of this study was to determine the type of bamboo plants and their utilization by the community in Babane Village, Samalantan District, Bengkayanag Regency. The method used in this research is direct survey method in the field. Data analysis technique is done by using descriptive explorative analysis by describing bamboo plant species. The results of this study can be found that 8 species of 4 genera: Bambusa vulgaris (yellow Tarenk), Bambusa multiplex (Aur) Dendocalamus asper (Betung), Schizotachyum zollinggeri (Buluh), Schizotachyum lima (pesak), Gigantochloa sp (Munti), Gigantochloa altroviolacea (Tarenk), Gigantochloa balui (Bangking). And its use is the making of webbing by artisans, antenna poles, animal cages, boards, making vegetables from rizom (bamboo shoots), and as an ornamental plant in the yard.
\end{abstract}

Keywords : Babane Village, Bamboo, ornamental plant.

\section{PENDAHULUAN}

Bambu merupakan salah satu hasil hutan non kayu yang banyak dimanfaatkan oleh masyarakat baik di pedesaan maupun perkotaan (Widjaja dan Karsono, 2005). Pemanfaatan bambu secara konvensional antara lain untuk pertanian, peternakan, perikanan, peralatan rumah tangga, konstruksi rumah sederhana, jembatan di pedesaan, sampai kerajinan tangan. Sementara itu pemanfaatan yang lebih modern antara lain untuk bahan baku kertas, tusuk gigi, tusuk sate, sumpit, bambu lamina, papan partikel, dan arang. Menurut hasil penelitian Iqbal dkk (2014) bambu dikenal sebagai hasil hutan bukan kayu yang pemanfaatannya sudah berlangsung lama dan sudah di gunakan turun temurun dari masa ke masa. Harga bambu juga relatif murah dibanding bahan bangunan lain karena banyak ditemukan di sekitar pemukiman pedesaan bahkan juga di perkotaan. Tanaman bambu di Indonesia ditemukan mulai dari dataran rendah sampai pegunungan. Pada umumnya bambu ditemukan di tempat-tempat terbuka dan daerahnya bebas dari genangan air.

Tanaman bambu hidup merumpun, mempunyai ruas dan buku. Pada setiap ruas tumbuh cabang-cabang yang berukuran jauh lebih kecil dibandingkan dengan buluhnya sendiri. Pada ruas-ruas ini tumbuh akar-akar sehingga pada bambu dimungkinkan untuk memperbanyak tanaman dari potongan- 
potongan ruasnya, disamping tunastunas rumpunnya.

Saat ini di Indonesia terdapat 157 jenis bambu endemik yang belum seluruhnya dikembangkan, diantaranya bambu eul-eul dari Bandung, Jawa Barat, Fimbribambusa di Meru Betiri, Jawa Timur dan Schizotachyum di Kalimantan Barat. Menurut hasil penelitian Yuliati (2004) Jenis -jenis bambu yang ditemukan di Kabupaten Bengkayang Desa Bengkawan, Kecamatan Seluas Kabupaten Bengkayang yaitu: bambu Aur oui (Bambu balcoa), bambu Pisak (Bambu glaucescens), bambu Betung (Dendrocalamus asper), bambu Paring (Gigantochloa apus), bambu Buluh (Schhizostachyum zolliNgeri), bambu Miang

(Schhizostachyum logipiculatum). Penelitian ini bertujuan Untuk mendapatkan data mengenai jenis bambu. Juga Untuk memperoleh data pemanfaatan bambu oleh masyarakat serta data mengenai bagian bambu yang diolah oleh Masyarakat Desa Babane Kecamatan Samalantan Kabupaten Bengkayang.

\section{METODE PENELITIAN}

Penelitian ini dilaksanakan dengan menggunakan metode deskriptif kualitatif melalui wawancara mendalam (indept survey) terhadap responden terpilih. Pemilihan responden menggunakan teknik snow ball sampling atau dilakukan secara berantai dengan meminta informasi pada orang yang telah diwawancarai sebelumnya, demikian seterusnya (Poerwandi, 1998). Selain itu dilakukan pencatatan mengenai keterangan jenis - jenis bambu yang dimanfaatkan masyarakat setempat (responden). Dalam penelitian ini peneliti akan meminta rekomendasi calon responden dari kepala desa,kepala adat, kepala dusun, orang tua, ibu - ibu dan lain - lain untuk mendapatkan informasi pemanfaatan bambu oleh masyarakat sebagai sumber data penulis.

Penelitian ini dilaksanakan di Desa Babane Kecamatan Samalantan Kabupaten Bengkayang. Waktu penelitian \pm 2 minggu efektif di lapangan mulai dari tanggal 12 September 2017 sampai dengan 26 september 2017. Pemilihan lokasi penelitian didasarkan pertimbangan bahwa di lokasi tersebut masih banyaknya rumpun bambu yang berpotensi sebagai sumber kebutuhan masyarakat.

\section{HASIL DAN PEMBAHASAN}

Berdasarkan hasil penelitian diperoleh delapan jenis bambu yang dimanfaatkan oleh masyarakat di Desa Babane yang berasal dari 4 genus yaitu Bambusa, Dendocalamus, Schizotachyum dan Gigantochloa. Pemanfaatan lebih banyak pada anyaman dan konsumsi dan bagian yang banyak digunakan adalah batang dan tunas seperti tersaji pada Tabel 1 berikut. 
Tabel 1. Hasil Penelitian Jenis Tumbuhan Bambu di Desa Babane Kecamatan Samalantan Kabupaten Bengkayang. (Research Results Bamboo Plant Species in Babane Village District Samalantan Bengkayang Regency).

\begin{tabular}{|c|c|c|c|c|c|}
\hline No & $\begin{array}{r}\text { Nama } \\
\text { daerah } \\
-1\end{array}$ & $\begin{array}{c}\text { Nama ilmiah } \\
-2\end{array}$ & $\begin{array}{c}\text { Genus } \\
-3\end{array}$ & $\begin{array}{c}\text { Lokasi } \\
\text { (Dusun) } \\
-4\end{array}$ & $\begin{array}{c}\text { Jenis pemanfaatan } \\
-5\end{array}$ \\
\hline & Tarenk & & & & \\
\hline 1 & kuning & Bambusa vulgaris & Bambusa & Sekumpit & Mistis \\
\hline 2 & Betung & Dendocalamus asper & Dendocalamus & Nekbare & $\begin{array}{l}\text { Konsumsi, kesenian, } \\
\text { papan }\end{array}$ \\
\hline 3 & Aur & $\begin{array}{l}\text { Bambusa multiplex } \\
\text { Schizotachyum }\end{array}$ & Bambusa & Nekbare & Kesenian \\
\hline 4 & Buluh & zollinggeri & Schizotachyum & Bantang & Kesenian, ritual adat \\
\hline 5 & Munti & Gigantochloa sp & Gigantochloa & Nekbare & Kesenian \\
\hline 6 & Pasak & Schizotachyum lima & Schizotachyum & Sekumpit & Kesenian \\
\hline 7 & Tarenk & Gigantochloa atter & Gigantochloa & Bantang & $\begin{array}{l}\text { Kesenian, konsumsi, } \\
\text { papan }\end{array}$ \\
\hline 8 & Bangking & Gigantochloa balui & Gigantochloa & Nekbare & Papan \\
\hline
\end{tabular}

Berdasarkan hasil penelitian diperoleh 8 jenis bambu yang dimanfaatkan oleh masyarakat di Desa Babane yang berasal dari 4 genus yaitu Bambusa, Dendocalamus, Schizotachyum dan Gigantochloa. Pemanfaatan lebih banyak pada anyaman dan konsumsi dan bagian yang banyak digunakan adalah batang dan Tabel 2. Bagian bambu yang dimanfaatkan (used bamboo parts)

\begin{tabular}{ccc}
\hline No & Jenis bambu & Bagian yang dimanfaatkan \\
& $(\mathbf{1})$ & Rebung \\
\hline 1 & Betung & Batang \\
2 & Aur & Batang,rebung \\
3 & Buluh & Batang,rebung \\
4 & Munti & Batang \\
5 & Tarenk & Batang \\
6 & Pasak & Batang \\
7 & Bangking & Batang \\
8 & Bambu kuning & \\
\hline
\end{tabular}

tunas. Bagian bambu yang dimanfaatkan di Desa Babane lebih banyak memanfaatkan batang bambu dan rebung. Tidak terdapat penggunaan akar, daun maupun bunga bambu hal ini dikarenakan kurangnya pengetahuan tersebut. masyarakat akan manfaatan bambu 


\section{Bentuk Pemanfaatan Bambu Oleh Masyarakat Babane}

Bambu merupakan tumbuhan yang banyak manfaatnya bagi kehidupan manusia diantaranya untuk membuat dapur (paceko), tempat untuk menjemur pakaian, pagar, bahan pengikat, koker/pot tanaman, alas untuk menjemur ikan hasil tangkapan dan pemenuhan kebutuhan bahan rumah tangga lainnya lihat pada table 3. Disamping itu bambu mempunyai manfaat bagi kehidupan manusia khususnya Masyarakat Desa Babane. Di Desa Babane sendiri belum memanfaatkan bambu secara optimal, kebanyakan masyarakat baru memanfaatkan bambu untuk pagar tanaman jagung, kacang dan padi tiang antena, jemuran, kandang peliharaan, konsumsi, ritual dan konsumsi. Belum ada masyarakat yang memanfaatkan bambu untuk dijadikan tambahan penghasilan seperti membuat tusuk gigi atau sumpit untuk dipasarkan atau memanfaatkan sendiri.

Bambu juga banyak digunakan pada upacara adat pernikahan dan kematian. Masih ada pula masyarakat yang menggunakannya sebagai bahan untuk membuat tempat memasak atau pengganti periuk (panci masak). Pemanfaatan bambu sebagai salah satu hasil hutan bukan kayu oleh masyarakat Desa Babane belum banyak berubah. Hal ini terkait dengan pengetahuan dan keahlian yang dimiliki oleh masyarakat yang masih sangat minim.

Berdasarkan hasil wawancara diperoleh pemanfatan bambu secara spesifik. Dari 8 jenis bambu yang dimanfaatkan terdapat jenis bambu yang pemanfaatannya lebih dari 1 manfaat seperti bambu Aur terdapat manfaat seni, konsumsi dan bahan papan. Bambu Buluh yang digunakan sebagai seni, konsumsi dan kebutuhan ritual. Munti dimanfaatkan sebagai konsumsi, kesenian dan papan. Namun terdapat jenis bambu yang tidak dimanfaatkan yaitu bambu kuning dimana bambu ini tumbuh dan masyarakat tidak memanfaatkan untuk keperluan seharihari seperti pada bambu lainnya.

\section{Jenis Bambu Betung dan Manfaatnya} Oleh Masyarakat Sebagai Konsumsi

Bambu betung atau Dendocalamus asper merupakan jenis bambu yang familiar di Indonesia. Bambu dengan rebung hitam keunguan, tertutup bulu berwarna coklat hingga kehitaman Bulu tingginya hingga $20 \mathrm{~m}$ tegak dengan ujung melengkung Widjaja (2001) Bambu Dendocalamus asper mempunyai rebung yang lebih baik untuk dijadikan sayuran dibandingkan dengan rebung bambu yang lain. Menurut Andoko (2003), rebung Dendocalamus asper merupakan rebung yang enak untuk dikonsumsi. Seperti yang tersaji pada gambar 1 . 

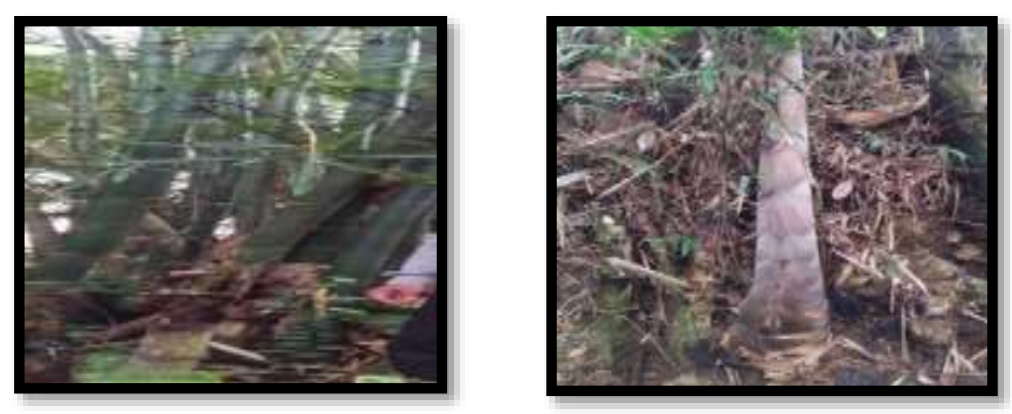

Gambar 1. Betung (Dendocalamus asper)

Di Desa Babane bambu betung dimanfaatkan oleh masyarakat sebagai sayuran saja. Masyarakat kurang terampil dalam mengolah atau memanfaatkan jenis bambu ini, hal ini menyebabkan masyarakat tidak memanfaatkan jenis bambu ini untuk keperluan kesenian atau anyaman. Masyarakat Babane hanya memanfaatkan rebung Dendocalamus asper sebagai sayur, sehingga jumlah populasinya terus berkurang. Sedangkan menurut Widjaja (2001) bagi orang Sunda dan orang Jawa rebungnya bias

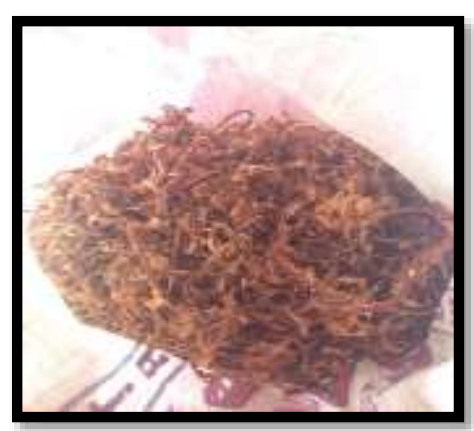

Gambar 2. Rebung Kering Rebung Basah (Dry bamboo shoots Wet bamboo shoots)

Masyarakat Desa Babane pada umumnya mengambil bambu hanya untuk memenuhi kebutuhan sendiri dan belum menjadi sumber pendapatan bagi masyarakat setempat. Meskipun aktivitas pemanfaatan bambu masih tergolong rendah, namun keberlangsungan fungsi tanaman bambu digunakan untuk sayur dan batang digunakan untuk pilar konstuksi bangunan, mebel, industry sumpit, tusuk gigi dan kertas. Selain itu juga digunakan untuk membuat alat musik bambu tradisional seperti Bas. Di Desa Babane bambu ini awalnya hidup liar di pegunungan maupun bukit-bukit, namun beberapa masyarakat sudah membudidayakan bambu ini di pekarangan rumah, karena masyarakat memanfaatkan rebung bambu betung sebagai konsumsi. Seperti yang tersaji pada gambar 2 .

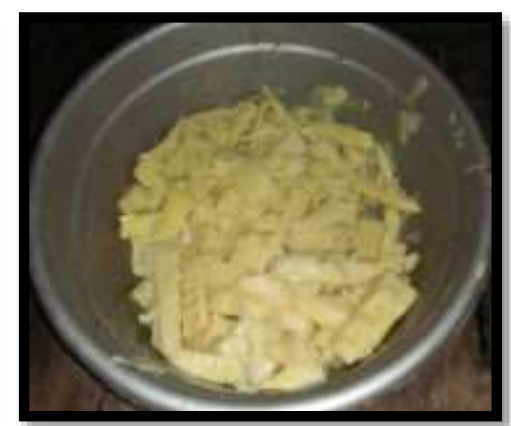

mengalami pengurangan jumlah populasi yang ada, karena selain dimanfaatkan sebagai bahan baku alatalat rumah tangga, masyarakat juga menebang bambu muda sebagai bahan sayuran (rebung), Rebung yang dikonsumsi di sini adalah rebung yang mempunyai tekstur agak lunak. Teknik 
pemotongan rebung yaitu memotong bagian bawah yang agak mengeras. Bagian yang terlalu keras memiliki rasa agak pahit. Bagian rebung yang dikonsumsi adalah bagian dalam yang berwarna keputihan, bagian ini lunak dan memiliki rasa yang enak.

Pemanfaatan bambu betung pada masyarakat di Desa Babane yaitu sebagai sayuran dari tunasnya, namun tidak semua jenis bambu yang ditemukan di Desa Babane dapat dimakan salah satu contoh rebung bambu bangking. Rebung bangking menurut penuturan responden terasa pahit sehingga tidak dimanfaatkan, selain itu rebung bambu kuning dan rebung bambu buluh juga tidak dapat dimanfaatkan sebagai sayuran. Selain diolah menjadi sayuran rebung bambu juga dibuat rebung kering hal ini untuk pengawetan secara alami.

Jenis Pemanfaatan Bambu Aur Oleh Masyarakat Babane Sebagai Anyaman

Bambu Aur atau Bambusa multiplex di Desa Babane merupakan bambu yang paling sering dijumpai. Bambu dengan rebung hijau, gundul. Buluh mencapai 8 $\mathrm{m}$, tegak dengan ujung melengkung ke bawah. Percabangan terletak pada bukubuku didekat tanah, setiap percabangan terdiri atas 7-9 cabang yang besarnya hampir sama Widjaja (2001). Bambu ini hidup di sepanjang tepi-tepi sungai Desa Babane. Seperti yang tersaji pada gambar 3 .

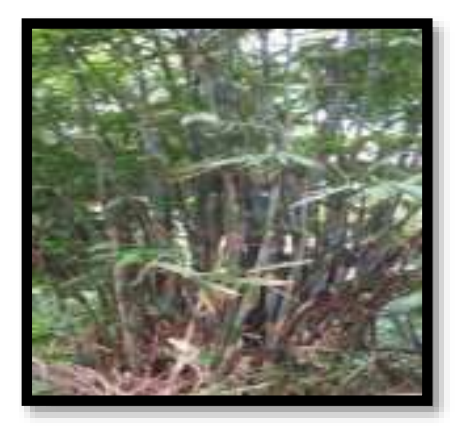

Gambar 3. Bambu Aur (Bambusa multiplex)

\begin{tabular}{|c|c|}
\hline $\begin{array}{l}\text { Masyarakat Desa } \\
\text { memanfaatkan bambu ini sebagai } \\
\text { anyaman Antiing, Bubu ikan, Alam } \\
\text { (talam), Ragak, Tangok, dan Luing. } \\
\text { Antiing merupakan alat penangkap ikan } \\
\text { yang berbentuk kerucut dengan ukuran } \\
\text { diameter sekitar } 1 \text { meter yang terbuat } \\
\text { dari bahan baku bambu aur dan } \\
\text { tambahan rotan. Pembuatan dengan cara } \\
\text { mengambil kulit bambu Aur sekitar } 2 \\
\text { atau } 3 \text { cm dengan panjang sekitar } 2-3 \\
\text { meter kemudian menganyam bambu } \\
\text { hingga terbentuk kerucut, rotan }\end{array}$ & $\begin{array}{l}\text { berfungsi sebagai penahan permukaan } \\
\text { Antiing. Bubu ikan memiliki fungsi yang } \\
\text { sama dengan antiing yaitu penangkap } \\
\text { ikan perbedaannya pada bentuknya. } \\
\text { Bubu ikan berbentuk selinder dan terbuat } \\
\text { dari seluruh batang bambu aur yang } \\
\text { dipotong memanjang dengan ukuran } 2 \\
\text { cm dengan panjang } 2 \text { meter permukaan } \\
\text { diberi rotan yang berbentuk bulat } \\
\text { sebagai penguat dan di dalamnya diberi } \\
\text { tutup dengan bentuk kerucut tertutup } \\
\text { agar ikan bisa masuk namun tidak bisa }\end{array}$ \\
\hline
\end{tabular}


anyaman dari bambu aur yang berfungsi sebagai nampan tempat bumbu-bumbu dan tempat menyimpan barang-barang lainnya yang terbuat dari kulit bambu aur yang di kuliti dari batangnya dan di jemur selama 1 hari lamanya dan dianyam sedemikian rupa dan mebutuhkan waktu 2-3 jam dalam
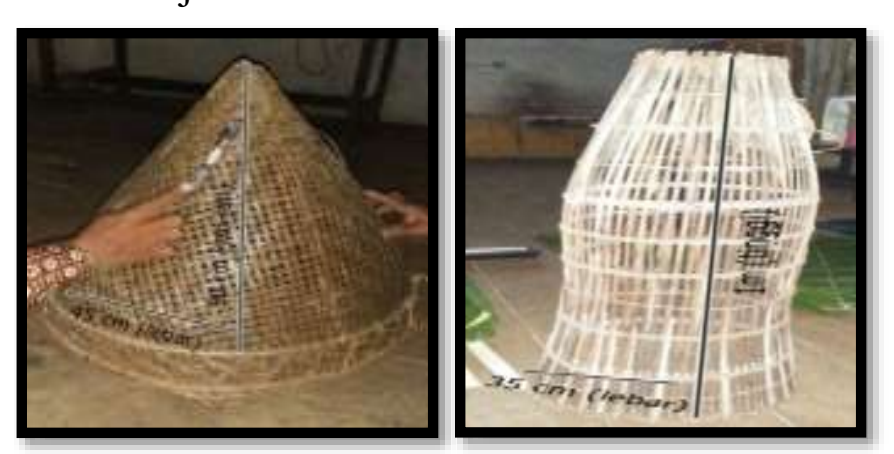

Gambar 4. Antiing dan Bubu ikan (Antiing and Fish Bubu)

Jenis Pemanfaatan Bambu Buluh Oleh

Masyarakat Babane Sebagai Anyaman dan Ritual

Rebung hijau dengan ujung kecoklatan, tertutup bulu coklat. Buluh tinggi mencapai $15 \mathrm{~m}$, lurus dan tegak, ujungnya melengkung dindingnya tipis 5 $\mathrm{mm}$. Bambu buluh atau Schizotachyum zollinggeri di Desa Babane dimanfaatkan sebagai anyaman dan ritual keagamaan. Keberadaan bambu buluh ini di Desa Babane terbilang cukup banyak. Karena masyarakat pengaymannya. Sedangkan menurut Widjaja (2001), bambu ini berguna sebagai tamanan pagar, tanaman hias, dan untuk kerajinan tangan seperti lemari, rak surat kabar dan juga joran pancing. Seperti yang tersaji pada gambar 4.

menanam dipekarangan rumah dan kebun mereka sendiri, karena dianggap banyak memiliki manfaat. Namun di Desa Babane teknik pembudidayaan semua jenis bambu tidak seperti pada daerah-daerah berkembang dalam industi pertaniannya seperti di daerah Jawa dan daerah-daerah lainnya. Karena tidak dibudidayakan untuk dikomersialkan, masyarakat menanam hanya untuk keperluan sehari-hari seperti anyaman, ritual dan konsumsi seperti yang tersaji pada Gambar 5. 


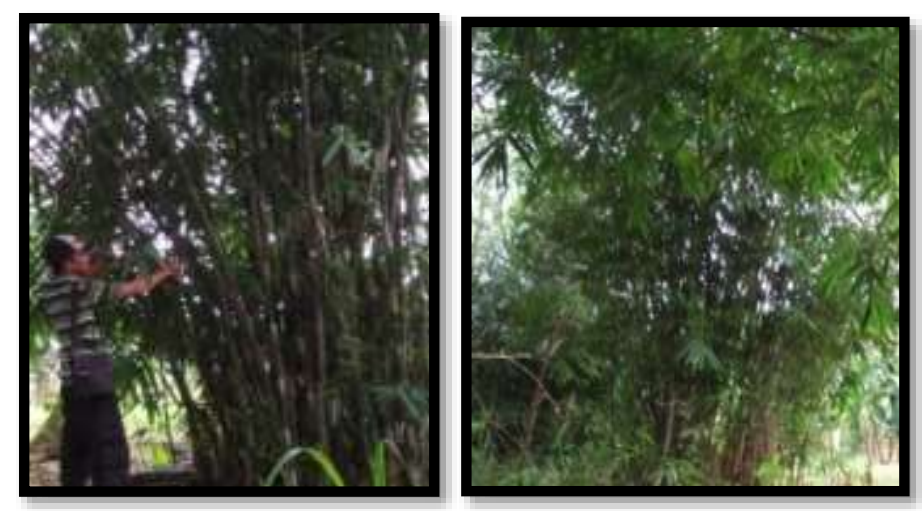

Gambar 5. Bambu buluh (Schizotachyum zollinggeri)

Masyarakat memanfaatkan Bambu Buluh sebagai anyaman seperti nyero, dako, tarinak, saringan, konse dan ritual keagamaan. Nyero merupakan alat penampi beras dan biji-biji lainnya seperti jagung dan kacang untuk menghilangkan kulit ari biji. Nyero motif merupakan padanan nyero biasa yang berukuran besar berbentuk lingkaran. Namun nyiro motif ini di buat dengan ukuran lebih kecil dan lebih menarik di anyam sesuai motif yang diinginkan. Pembuatannya walau lebih kecil dari nyero biasa lebih sulit dan membutuhkan konsentrasi yang cukup dan pembuatannya harus pada malam hari, karena menurut keyakinan masyarakat Desa Babane pada malam hari fikiran lebih jernih tanpa ada suara dan gangguan. Dan pembuatannya memmerlukan 2-3 malam untuk satu nyero bermotif ini dan harga satu nyero ini Rp 60.000, namun nyero ini oleh Masyarakat Babane tidak dijual hanya untuk koleksi dan sebagai perabotan rumah saja. Seperti yang tersaji pada gambar 6 .

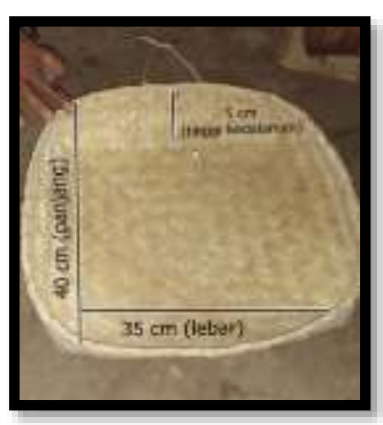

Gambar 6. Nyiro' dan Dako (Nyiro end dako)

Salah satu bambu yang dimanfaatkan sebagai kebutuhan upacara ritual adalah Bambu Buluh. Bambu Buluh yang digunakan sebagai upacara ritual merupakan pelengkap saat upacara berlangsung, hampir semua kegiatan ritual di Desa Babane menggunakan Bambu Buluh. Di Desa babane pemanfaatan bambu buluh sebagai ritual mendirikan tiang rumah 
baru yang pertama yaitu dengan memasak lemang di dalam buluh kemudian lemang tersebut disimpan didekat tiang rumah baru bersama tumpi (cucur) kemudian pasirah memanjatkan doa-doa. Selain itu Bambu Buluh juga dimanfaatkan sebagai wadah penyimpan air carabo (air suci) yang telah dibacakan doa-doa. Setelah selesai upacara ritual adat air yang terdapat di dalam bambu dituang ke tangan untuk membersihkan tangan pasirah. Dalam upacara ritual kelahiran dan kematian bambu ini juga digunakan sebagai pelengkap untuk sesajen dalam memanjatkan doa yang dikenal dengan Nyagahant oleh masyarakat Desa Babane dalam bentuk lemang.

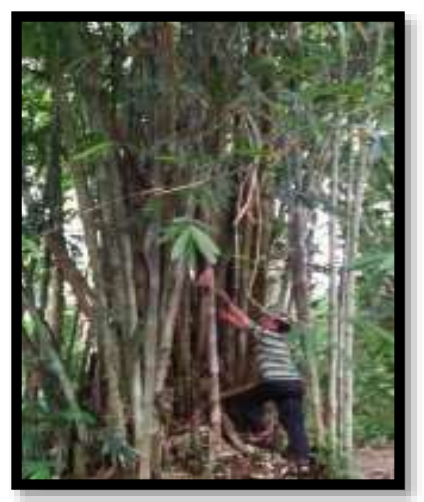

Gambar7.Bambumunti (Schizotachyum sp)

Di Desa Babane bambu yang dimanfaatkan sebagai papan yaitu jenis bambu yang keras seperti bambu betung, bambu aur dan bambu munti. Bambu tersebut dimanfaatkan sebagai lantai teras rumah namun ada juga yang menggunakan sebagai kandang peliharaan hewan seperti kandang ayam

\section{Jenis Pemanfaatan Bambu Munti (Schizotachyum sp) Sebagai Papan dan Sayur}

Rebung hijau muda dengan ujung kecoklatan. Batang tingginya mencapai 10-12 m. terdapat jauh dipermukaan tanah, ruas panjangnya 50-70 cm dengan diameter 10-15 cm. Bambu Munti di Desa Babane merupakan bambu dari hasil tanaman masyarakat, pemanfaatan bambu ini yaitu sebagai sayuran dan pagar kandang ayam, kandang babi, panyah dan bangkat. Menurut Widjaja (2001), Schizotachyum sp sudah digunakan untuk industri sumpit dan rebungnya bisa dicampur dengan rebung bambu Dendocalamus asper untuk dimakan Seperti yang tersaji pada gambar 7 .

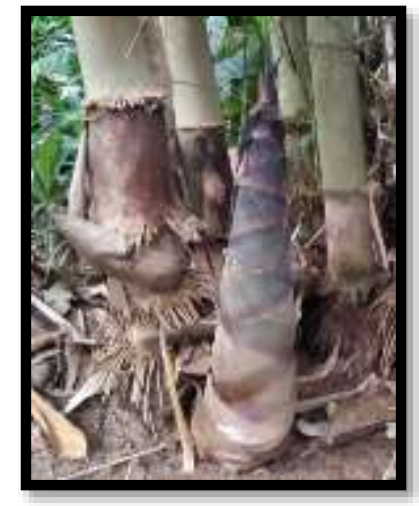

dan kandang babi. Karena disamping batangnya yang keras dan lebih tahan terhadap serangan rayap, juga bamabu Munti keberadaanya di Desa Babane juga cukup baik pertumbuhannya. oleh karena itu masyarakat memanfaatkan bambu munti sebagai papan. Seperti yang tersaji pada gambar 8 . 

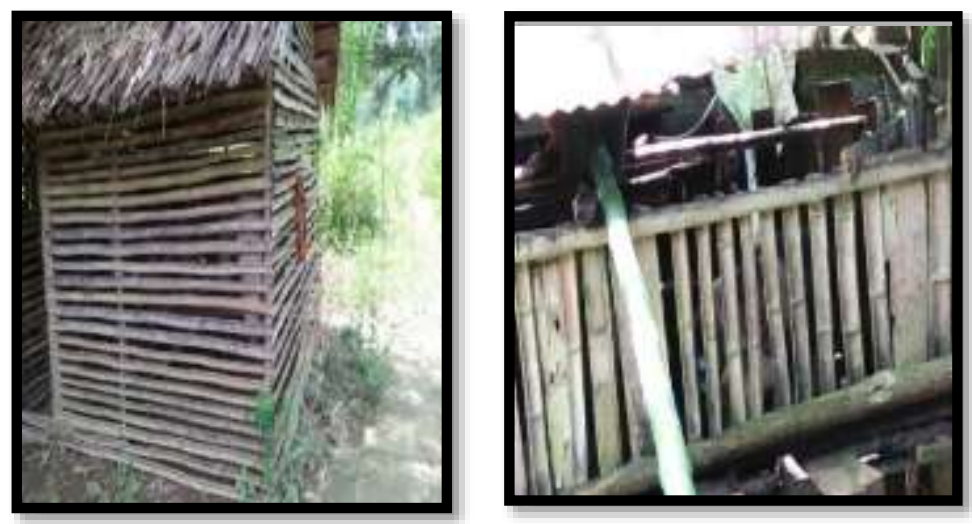

Gambar 8. Kandang hewan Ternak(Animal cage livestock)

Bentuk pemanfaatan bambu pada masyarakat Desa Babane Kecamatan Samalantan Kabupaten Bengkayang dapat dilihat pada table 3. Dimana dari semua jenis bambu yang ada didesa babane semuanya dimanfaatkan oleh masyarakt setempat mulai dari konsumsi sampai pada penggunaan ritual adat dan sebagai bahan dasar kerajinan tangan tersendiri. Dari semua jenis bambu yang berada didea babane memberikan pengaruh tersendiri kepada setiap pengguna yang berada didesa tersebut. 
Tabel 3 . Bentuk pemanfaatan bambu di desa babane. ( from of utilization fo bamboo inbabane village.)

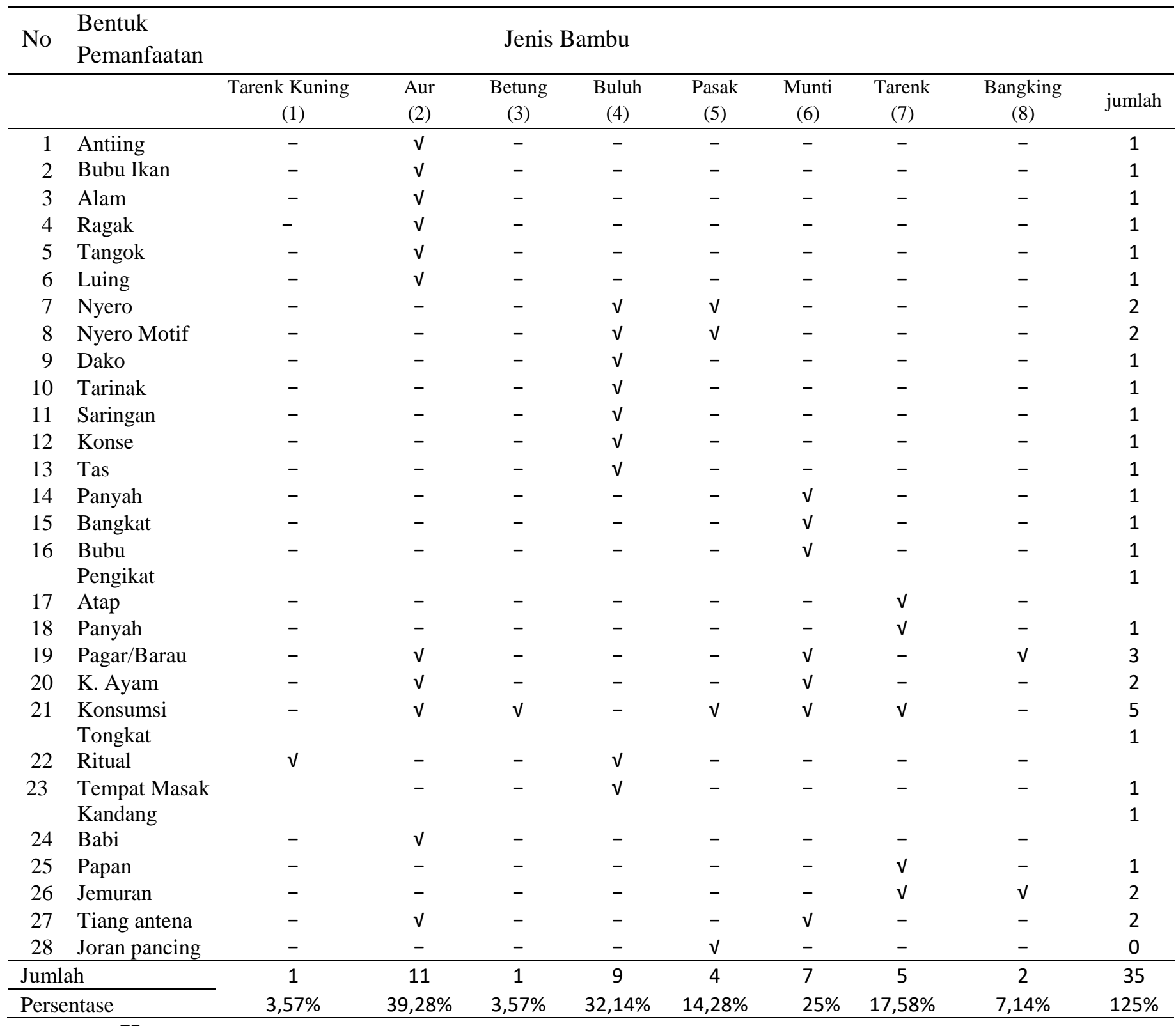

\section{Keterangan:}

$\checkmark$ Menggunakan bambu

- Tidak menggunakan bambu

\section{Manfaat Bambu Secara Sosial Ekonomi}

Tanaman bambu baik dalam skala kecil maupun besar mempunyai nilai ekonomi yang meyakinkan. Budaya masyarakat menggunakan bambu dalam berbagai aktivitas kehidupan sehingga bambu dapat dikategorikan sebagai multipurpose Tree species $(\mathrm{MPTS}=$ jenis pohon yang serbaguna). 
Pemanfaatan bambu secara tradisional masih terbatas sebagai bahan bangunan dan kebutuhan keluarga lainnya (alat rumah tangga, kerajinan,alat kesenian seperti angklung, calung, suling, gambang, bahan makanan seperti rebung dll.). Pada umumnya jenis-jenis bambu yang diperdagangkan adalah jenis bambu yang berdiameter besar dan berdinding tebal. Jenis-jenis tersebut diwakili oleh warga Bambusa, Dendrocalalamus dan Gigantochloa. Berdasarkan jenis-jenis tersebut dapat dibudidayakan secara massal untuk menunjang industry kertas, chopstick, flowerstick, ply bamboo, particle board dan papan semen serat bambu serta kemungkinan dikembangkan bangunan dari bahan bambu yang tahan gempa dll.

Keberadaan Tumbuhan Bambu di Desa Babane

Berdasarkan penuturan salah satu responden selama berada di lapangan yang dilakukan kegiatan penanaman bambu Masyarakat Babane juga tidak begitu istimewa. Bahkan ada dari masyarakat yang hanya sekali tanam seumur hidup. Walaupun sebenarnya bambu dapat dikembangkan melalui biji, stek batang, stek cabang, stump dan melalui kultur jaringan dan pembuatan lubang tanam sebaiknya mengikuti arah kontur dan dibuat dengan jarak 40 x 40 $\mathrm{cm}$ atau 50 x $50 \mathrm{~cm}$ sampai $100 \times 100 \mathrm{~cm}$ dengan kedalaman 40-50 cm (Departemen Kehutanan Balai Rehabilitasi Lahan Dan Konservasi Tanah Wampu Sei Ular, 2004) Namun kebanyakan masyarakat Desa Babane hanya menanam bambu melalui tunas dan juga stek batang dimana mereka menanam hanya dengan patokan dimna merek mau di kebun ataupun dipekarangan rumah.

Dari hasil wawancara dengan responden tidak ada kegiatan intensif yang dilakukan oleh masyarakat karena memang tanaman bambu sudah tumbuh liar sejak lama dan juga sangat subur. Adapun kegiatan pembersihan lahan yang dilakukan hanya semata-mata untuk melihat anakan bambu tersebut. Yaitu dengan tujuan agar bisa mengambil anakan bambu untuk diolah menjadi sayuran seperti sayur rebung bambu yang diambil dari anakan bambu.

\section{Kesimpulan}

1. Berdasarkan data yang diperoleh di lokasi penelitian tercatat 7 jenis bambu yang dimanfaatkan oleh masyarakat Desa Babane Kecamatan Samalantan Kabupten Bengkayang dari 8 jenis bambu yang ditemukan.

2. Pemanfaatan dan pengolahan bambu untuk bahan kerajinan anyaman dan pemanfaatan lainya membantu masyarakat dalam kehidupan sehari-hari. Jenis-jenis bambu yang digunakan oleh masyarakat adalah bambu Betung atau Dendocalamus asper dimanfaatakan sebagai konsumsi. Aur atau Bambusa multiplex dimanfaatkan sebagai anyaman. Buluh atau Schizotachyum zollinggeri dimanfaatkan sebagai kesenia, ritual adat. Munti atau Gigantochloa sp dimanfaatkan sebagai kesenian atau anyaman, 
konsumsi dan papan. Pasak atau Schizotachyum lima dimanfaatkann sebagai kesenian. Tarenk atau Gigantochloa altroviolacea dimanfaatkann sebagai kesenian, konsumsi dan papan. Bangking atau Gigantochloa balui dimanfaatkan dalam bentuk papandan.

3. Dari kedelapan jenis bambu yang ada di desa Babane Kecamatan Samalantan Kabupaten Bengkayang semuanya di manfaatkan oleh masyarakat setempat dalam berbagai keperluan sehari-hari mulai dari peralatan rumah tangga, sayuran, kesenian dan ritual keagamaan.

\section{Saran}

Berdasarkan hasil penelitian dikemukakan saran-saran sebagai berikut.

1. Untuk jenis bambu yang banyak digunakan diharapkan masyrakat Desa Babane Kecamatan Samalantan Kabupten Bengkayang dapat melakukan pembudidayaan bambu agar keberadaan bambu tersebut tetap ada dan terus dimanfaatkan secara berkelanjutan.

2. Untuk jenis kerajian anyaman dan bentuk pemanfaatan lainya dari bambu, diharapkan masyarakat sadar akan pentingnya bambu dan membudidayakan secara berkelanjutan, melihat begitu pentingnya peranan bambu ditengah-tengah kehidupan masyarakat Indonesia khususnya masyarakat Desa Babane Kecamatan Samalantan Kabupten Bengkayang.

3. Perlu adanya peran serta dan inisiatif pemerintah daerah dan dinas yang terkait terhadap pelestarian tanaman bambu guna mempertahankan keeksistensian tanaman bambu sebagai bagian dari kehidupan masyarakat setempat guna untuk menjadikan bambu sebagai kerajian dan sumber pendapatan bagi Masyarakat Babane.

\section{DAFTAR PUSTAKA}

Widjaja, E. A. dan Karsono. 2004. Keanekaragaman bambu di Pulau Sumba. Jurnal Biodiversitas, 6 (2): 95-99.

Iqbal, M. dkk. 2014. Nilai Ekonomi Total Sumberdaya Bambu Di Kecamatan Sajira, Kabupaten Lebak, Banten. Jurnal Mahasiswa Fakultas Kehutanan IPB.

Yuliati. 2004. Indentifikasi Jenis Bambu Di Desa Bengkawan Kecamatan Seluas Kabupaten Bengkayang. Skripsi Fakultas Kehutanan Universitas Tanjungpura Pontianak.

Andoko (2003), Teknik budidaya bamboo penghasil rebung sebagai sumber pangan.sumatra utara. 1722. Jurnal Teknologi dan Kejuruan

Poerwandari, E. K. 1998. Metode Penelitian Sosial. Universitas Terbuka: Jakarta. 